\title{
P276-00, a cyclin-dependent kinase inhibitor, modulates cell cycle and induces apoptosis in vitro and in vivo in mantle cell lymphoma cell lines
}

Nitesh P Shirsath ${ }^{1}$, Sonal M Manohar ${ }^{1}$ and Kalpana S Joshi $2^{*}$

\begin{abstract}
Background: Mantle cell lymphoma (MCL) is a well-defined aggressive lymphoid neoplasm characterized by proliferation of mature B-lymphocytes that have a remarkable tendency to disseminate. This tumor is considered as one of the most aggressive lymphoid neoplasms with poor responses to conventional chemotherapy and relatively short survival. Since cyclin D1 and cell cycle control appears as a natural target, small-molecule inhibitors of cyclin-dependent kinases (Cdks) and cyclins may play important role in the therapy of this disorder. We explored P276-00, a novel selective potent Cdk4-D1, Cdk1-B and Cdk9-T1 inhibitor discovered by us against MCL and elucidated its potential mechanism of action.
\end{abstract}

Methods: The cytotoxic effect of P276-00 in three human MCL cell lines was evaluated in vitro. The effect of P276-00 on the regulation of cell cycle, apoptosis and transcription was assessed, which are implied in the pathogenesis of MCL. Flow cytometry, western blot, immunoflourescence and siRNA studies were performed. The in vivo efficacy and effect on survival of P276-00 was evaluated in a Jeko-1 xenograft model developed in SCID mice. PK/PD analysis of tumors were performed using LC-MS and western blot analysis.

Results: P276-00 showed a potent cytotoxic effect against MCL cell lines. Mechanistic studies confirmed down regulation of cell cycle regulatory proteins with apoptosis. P276-00 causes time and dose dependent increase in the sub G1 population as early as from $24 \mathrm{~h}$. Reverse transcription PCR studies provide evidence that P276-00 treatment down regulated transcription of antiapoptotic protein Mcl-1 which is a potential pathogenic protein for MCL. Most importantly, in vivo studies have revealed significant efficacy as a single agent with increased survival period compared to vehicle treated. Further, preliminary combination studies of P276-00 with doxorubicin and bortezomib showed in vitro synergism.

Conclusion: Our studies thus provide evidence and rational that P276-00 alone or in combination is a potential therapeutic molecule to improve patients' outcome in mantle cell lymphoma.

Keywords: Mantle cell lymphoma, Cdk inhibitors, P276-00, Cyclin D1, Mcl-1

\footnotetext{
* Correspondence: kalpana.joshi@piramal.com

${ }^{2}$ Target Identification Group, Piramal Healthcare Limited, 1-Nirlon Complex,

Goregaon (E), Mumbai 400 063, India

Full list of author information is available at the end of the article
} 


\section{Background}

Mantle cell lymphoma (MCL), an aggressive B-cell malignancy constitutes about 4-10\% of all non-Hodgkin lymphomas (NHLs) population [1]. It exemplifies its clinical onset by a typical gathering of CD20+/CD5+ B cells in lymph nodes, spleen, bone marrow, and blood [2]. Classic (80-90\% cases) and blastoid (10-20\% cases) are the two powerful variants recognized where the latter is associated with inferior clinical outcome and poor prognosis [1,3-5]. Although treatment with combination chemotherapeutic regimens can be effective, virtually all patients relapse and the outcome of patients remains poor, with a median survival of only 3-5 years [6,7]. Currently available therapies including high-dose chemotherapy followed by stem cell transplant, and monoclonal antibody therapy have shown limited success $[2,8]$. No therapy has been effective enough to extend the overall survival time of patients with MCL. Thus, it remains incurable with current therapeutics available and awaits more effective treatment approaches [9].

Chromosomal translocation $\mathrm{t}(11 ; 14)(\mathrm{q} 13 ; 32)$ between the $\mathrm{IgH}$ and $\mathrm{Bcl}-1$ genes, which results in constitutive overexpression of cyclin D1, represents the hallmark of MCL and seemingly one of the critical oncogenic event, making MCL a genomically highly unstable disease [10-13]. Cyclin D1 coupled with Cdk4 regulates the G1-S transition of the cell cycle and hence this overexpression of cyclin D1 in MCL was thought to contribute to uncontrolled growth. Cyclin D1 overexpression contributes to the lymphomagenesis in MCL by overcoming the suppressor effect that retinoblastoma protein (RB) performs in the G1/S transition [1,14]. RB1 seems to be normally expressed in the majority of MCL cases and the protein appears to be hyperphosphorylated [15], particularly in highly proliferative blastic variants [16]. Enhanced proteolytic degradation of Cdk inhibitors such as p27 and p21 is also observed in MCL [17]. The expression of antiapoptotic members of the Bcl-2 family appears to be one important factor in the acquisition of clinical resistance by MCL cells [18]. From a mechanistic perspective, high levels of expression of the antiapoptotic protein Mcl-1 have been shown to correlate with high-grade morphology and a high proliferative state in MCL $[17,19]$. In addition, constitutively active STAT3 contributes to the malignant phenotype of MCL by promoting uncontrolled cell growth and survival through dysregulated protein expression, including that of interleukins viz; IL-6 and IL-10 [7].

P276-00, a novel small molecule inhibitor of cyclindependent kinases (Cdks), is currently in Phase II clinical trials. It shows better selectivity towards Cdk9-T1, Cdk4-D1 and Cdk1-B as compared with Cdk7-H and Cdk2-E [20,21]. Recently, we showed that it inhibits transcription in multiple myeloma cells by inhibiting
Cdk9-T1 which plays a positive regulatory role in transcription [22]. In the present study, we have evaluated and efficacy of P276-00 against MCL. Our hypothesis is that P276-00 being a potent Cdk4-D1 inhibitor will induce rapid cell death in MCL cells which overexpress cyclin D1. Also, its ability to down regulate anti-apoptotic protein Mcl-1 would contribute to its cytotoxic activity for MCL cells. Thus, we provide in vitro and in vivo evidence for use of P276-00 as a promising therapeutic agent for the treatment of patients with MCL.

\section{Results and discussion \\ Results \\ Cytotoxic potential of P276-00 against MCL}

All the three MCL cell lines in the presence of increasing concentrations of P276-00 showed significant dosedependent cytotoxicity as compared to vehicle treated cells $(p<0.0001)$. P276-00 resulted in dose and time dependent cytotoxicity with inhibitory concentration of $50 \%\left(\mathrm{IC}_{50}\right)$ ranging from $0.35 \mu \mathrm{mol} / \mathrm{L}$ in Jeko- 1 and Mino and $0.5 \mu \mathrm{mol} / \mathrm{L}$ in Rec-1 after $48 \mathrm{~h}$ (Figure 1A, B, C, Table 1). Earlier, we have shown that P276-00 is less cytotoxic to resting hPBMCs as compared to conconavalin A (ConA) stimulated hPBMCs [22,23]. These data indicate that P276-00 selectively induces higher cytotoxicity in proliferating cells viz. MCL cells and stimulated hPBMCs, but lesser in quiescent (unstimulated) hPBMCs.

Jourdan and colleagues [5] reported that interleukin-6 (IL-6) and insulin-like growth factor-1 (IGF-1) aggravate growth and prevent apoptosis in MCL cells. Treatment of MCL cells with P276-00 overcomes this protective effect of IL- 6 and IGF-1 as observed with no change in $\mathrm{IC}_{50} \mathrm{~S}$ in presence of IL- 6 and IGF-1 on MCL cell growth (data not shown).

\section{P276-00 inhibited the expression of positive regulators of cell cycle and short-lived oncoproteins}

Previous studies showed that transcriptional inhibition of anti-apoptotic proteins is a key mechanism for Cdk9 inhibitor-induced cell death in indolent B-cell malignancies [22]. P276-00 being a potent inhibitor of Cdk9-T1, we studied its effect on MCL cells. It significantly inhibited the phosphorylation of RNA Pol II CTD $6 \mathrm{~h}$ onwards and continued till 18 and $24 \mathrm{~h}$ of treatment (Figure 2A, B, and C). Recently, we have shown similar results in multiple myeloma cells and results were attributed to higher selectivity of P276-00 for Cdk9 than Cdk7, which is responsible for serine 5 phosphorylation of CTD of RNA Pol II [20,22]. In MCL cells levels of cyclin T1 were also significantly reduced at all the three time points. Owing to inhibition of transcription, rapid down regulation of a short-lived protein $\mathrm{Mcl}-1$ was observed especially in Jeko-1 cells. P276-00 being a potent Cdk inhibitor we studied its effect on cell cycle proteins and 
A

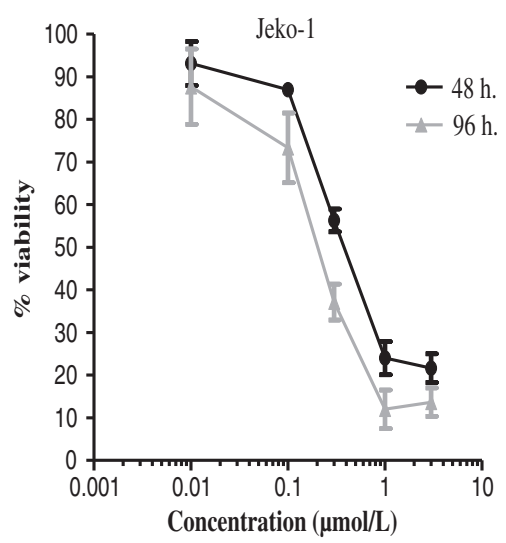

C

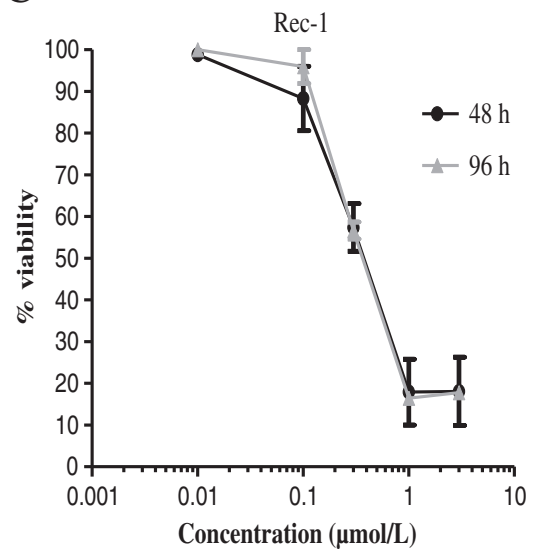

B

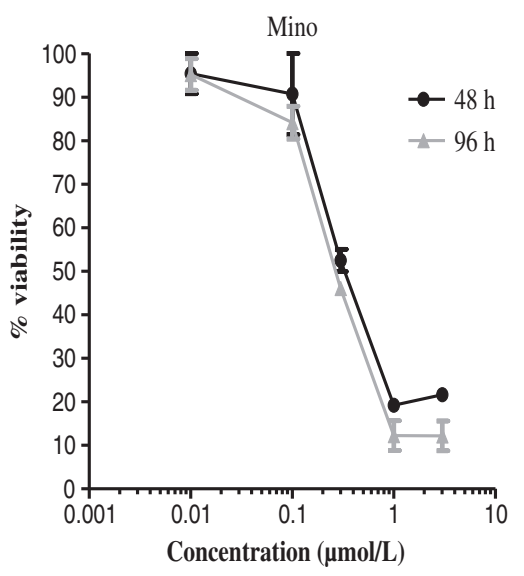

Figure 1 P276-00 mediated cytotoxic effect in MCL cell lines: Dose and time dependent analysis. The effect of P276-00 on viability of MCL cells was determined by CCK8 assay. Mantle cell lymphoma cell lines (A) Jeko-1, (B) Mino, and (C) Rec-1 were cultured in the presence of increasing concentrations of P276-00 (0.01-3 $\mathrm{mol} / \mathrm{L})$ for 48 and $96 \mathrm{~h}$. P276-00 showed IC 50 of $0.35 \mu \mathrm{mol} / \mathrm{L}$ at $48 \mathrm{hr}$ and $0.22 \mu \mathrm{mol} / \mathrm{L}$ at $96 \mathrm{hr}$ in Jeko-1 cells. In Mino and Rec-1 the $\mathrm{IC}_{50}$ were $0.5 \mu \mathrm{mol} / \mathrm{L}$ at $48 \mathrm{hr}$ and $0.21-0.33 \mu \mathrm{mol} / \mathrm{L}$ at $96 \mathrm{hr}$ (Table 1). Data presented as the average \pm SE of three independent experiments.

kinases. There was significant down regulation of cyclin $\mathrm{D} 1$ protein levels and $\mathrm{pRb}^{\mathrm{Ser} 780}$ which was also confirmed by immunofluorescence in Mino after $6 \mathrm{~h}$ of treatment (Figure 2D). Cdk4 levels were decreased in Jeko-1 cells after $6 \mathrm{~h}$ and after $24 \mathrm{~h}$ in Mino and Rec-1 cells. Interestingly p21 and p27 proteins were found to be increased after P276-00 treatment in Jeko-1 and Mino cells respectively at $\mathrm{IC}_{50}$ concentration. Mino cells which

Table 1 IC $_{50}$ ( $\mu \mathrm{mol} / \mathrm{L}$ ) for P276-00 and roscovitine in Mantle cell lymphoma cell lines

\begin{tabular}{lccccc}
\hline Cell & \multicolumn{2}{c}{ P276-00 } & & \multicolumn{2}{c}{ Roscovitine } \\
\cline { 2 - 3 } \cline { 6 - 6 } & $\mathbf{4 8} \mathbf{h}$ & $\mathbf{9 6} \mathbf{h}$ & & $\mathbf{4 8} \mathbf{h}$ & $\mathbf{9 6} \mathbf{~ h}$ \\
\hline Jeko-1 & $0.35 \pm 0.047$ & $0.21 \pm 0.055$ & & $25.3 \pm 1.83$ & $18 \pm 2.82$ \\
Mino & $0.5 \pm 0.28$ & $0.25 \pm 0.01$ & & $18.1 \pm 4.38$ & $14.56 \pm 4.55$ \\
Rec-1 & $0.5 \pm 0.24$ & $0.33 \pm 0.028$ & & $32 \pm 1.0$ & $40.1 \pm 1.27$ \\
\hline
\end{tabular}

harbour wild type p53 showed marked increase in p53 levels (Figure 2B). Increase in the levels of cleaved PARP, a marker for apoptosis was observed in Jeko-1 and Rec-1 cells concomitant with apoptotic cell death. Of all the three cell lines, Rec-1 cell line was found to be the most sensitive. It showed significant down regulation of key proteins such as $\mathrm{pRb}^{\mathrm{Ser} 780}$, cyclin T1 and pRNA pol $\mathrm{II}^{\text {Ser } 2 / 5}$ after as early as $6 \mathrm{~h}$ of treatment.

\section{P276-00 treatment induces apoptosis of MCL cells in a time- and dose-dependent manner}

Cell cycle analysis was performed on MCL variant cells after P276-00 treatment. As demonstrated in Figure 3A, B, C and D P276-00 causes induction of apoptosis in asynchronous population of MCL cell lines when exposed to $\mathrm{IC}_{50}$ and 3 times $(3 \mathrm{X}) \mathrm{IC}_{50}$ concentrations. P276-00 resulted in an increase in sub-G1 cells at as 


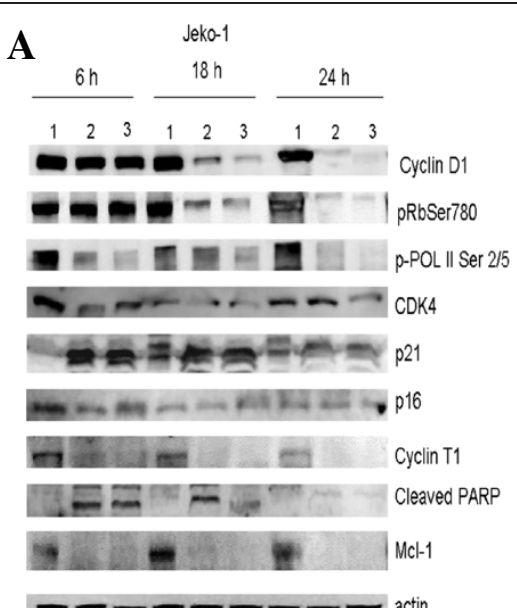

B

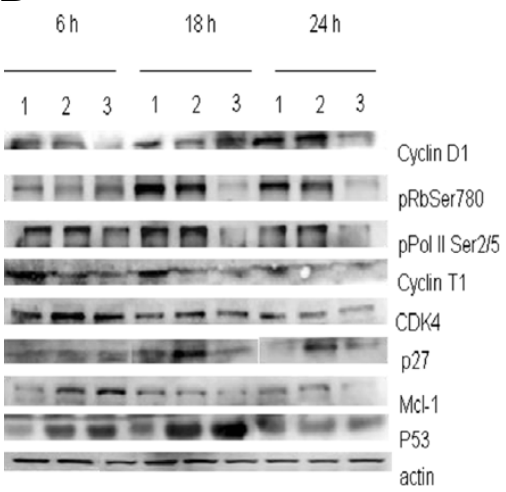

C

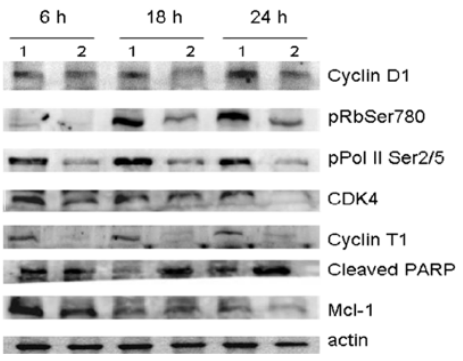

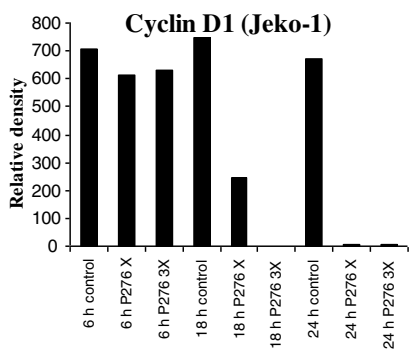
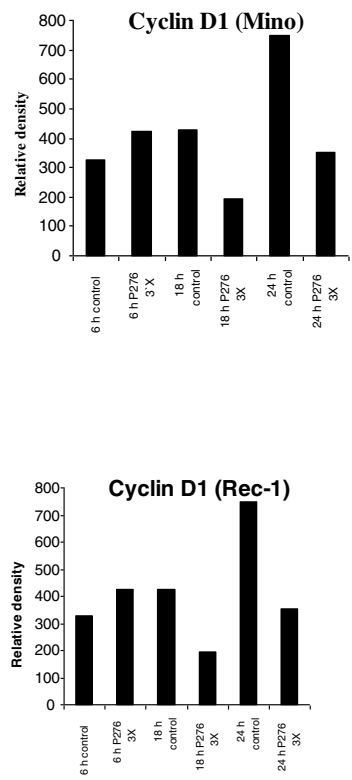

D

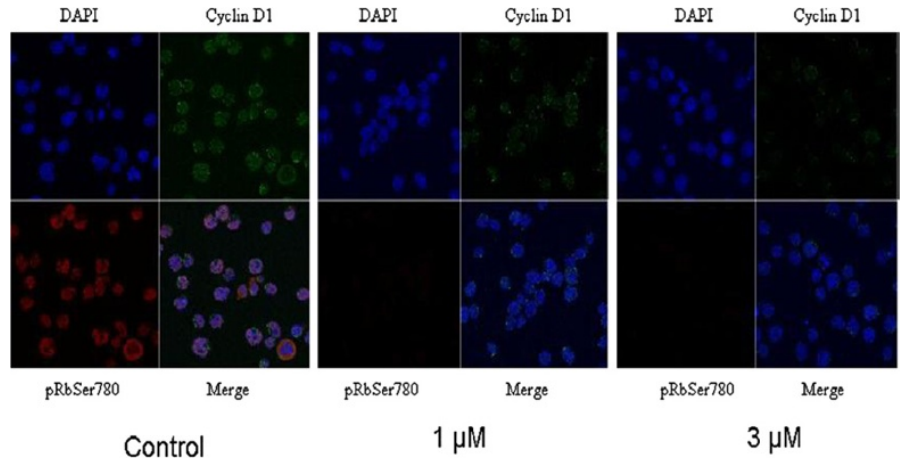

Figure 2 (See legend on next page.) 
(See figure on previous page.)

Figure 2 P276-00 on positive regulators of cell cycle along and anti-apoptotic protein: Western blot analysis of cell cycle proteins at designated time intervals after treatment of (A) Jeko-1, (B) Mino and (C) Rec-1 cells with P276-00. Jeko-1 and Mino cells (1-Control, 2- $C_{50}$ treated and 3- 3X $I C_{50}$ ) were incubated with 0.3 and $1 \mu \mathrm{mol} / \mathrm{L}$ P276-00 followed by protein isolation for Western blotting. Rec-1 cells (1-control and 2- treated) were treated at $1.5 \mu \mathrm{mol} / \mathrm{L}\left(3 X \mid \mathrm{C}_{50}\right)$ of P276-00 and it showed marked decrease in all cell cycle related protein level in time dependent manner. Marked down regulation of anti apoptotic protein, Mcl-1, were also seen from early time point in all three cell lines. Densitometric analysis of cyclin D1 expression was done using ImageJ software. (D) Regulation of cyclin D1 protein levels and Rb phosphorylation by P276-00 was confirmed by immunofluorescence in Mino after 6 h of treatment. Blue: DAPI (nuclear stain); Green: cyclin D1; Red: pRb Ser780.

early as $24 \mathrm{~h}$ with maximal effect noted at 48 and $96 \mathrm{~h}$ (70-80\% sub-G1 fraction). P276-00 doesn't allow cells to enter $\mathrm{G} 1$ phase and causes significant shift of cells from $\mathrm{G}_{0}-\mathrm{G} 1$ phase to sub-G1 phase.

\section{P276-00 rapidly down regulates $\mathrm{Mcl}-1$ transcription}

To confirm that the loss of Mcl-1 protein was due to decreased in transcription, the levels of Mcl-1 mRNA following P276-00 treatment were measured by reversetranscription PCR. Tubulin was used as a control. P276-00 caused a rapid reduction of Mcl-1 mRNA in Jeko-1 cell line from $6 \mathrm{~h}$ of treatment with the levels further decreasing up to $24 \mathrm{~h}$. It confirmed that the loss of Mcl-1 protein was due to a block in transcription (Figure 4A, B).

\section{Effect of siRNA depletion of Mcl-1 and cyclin D1 on survival of MCL cells}

Further we proposed to validate role of cyclin D1 and Mcl-1 in MCL survival using RNA interference (RNAi) approach. siRNAs against Mcl-1 and cyclin D1, which are critical proteins for MCL survival and proliferation, reduced respective protein levels by $60 \%$ in Jeko- 1 (Figure 4C). There was significant reduction of cell viability at 24 and $48 \mathrm{~h}$ with Mcl-1 siRNA and cyclin D1 siRNA at $48 \mathrm{~h}$ post transfection. These results highlight the crucial role of Mcl-1 and cyclin D1 in survival of MCL cells. When siRNA treatment was combined with P276-00 significant decrease in percentage survival of cells was observed compared to scrambled siRNA treatment (Figure 4D). Cyclin D1 and Mcl-1 siRNA treated cells in combination with P276-00 showed significant growth reduction at $24 \mathrm{~h}$. At later time point of $48 \mathrm{~h}$, P276-00 with Mcl-1 siRNA showed marked reduction in survival as compared to drug alone (Figure 4D).

\section{Anti-tumor effect of P276-00 in xenograft model of MCL}

In vivo P276-00 showed significant tumor growth inhibition of $91 \%$ at $50 \mathrm{mg} / \mathrm{kg}$ with stable disease throughout the schedule (Figure 5A and B). Kaplan Meier survival curve graph (Figure $5 \mathrm{~B}$ ) showed that mice treated with $50 \mathrm{mg} / \mathrm{kg}$ P276-00 ( $\mathrm{n}=10)$ have a median survival of 68 days (95\% confidence interval), which is significantly longer than the median survival of 58 days ( $95 \%$ confidence interval) in control SCID mice. The log-rank test indicated an overall statistically significant difference in survival of
P276-00 treated group as compared to vehicle treated group ( $\left.{ }^{*} p=0.0366\right)$. In PK-PD studies, intratumoral levels of P276-00 reached beyond its effective concentration (Figure 5E) which correlates effectively with significant down regulation of positive regulators of cell cycle (Figure 5C and D).

\section{Bortezomib and doxorubicin synergize the cytotoxic effect of P276-00 in MCL}

We next combined P276-00 with bortezomib and doxorubicin at suboptimal doses. Results indicate that the combination was synergistic as studied by Chou-Talalay method to calculate combination index (CI) [24]. Bortezomib (100 nM) and doxorubicin (1000 nM) with P27600 showed synergism with $\mathrm{CI}$ values ranging from 0.56 to 0.83 (Figure 6A and 6B).

\section{Discussion}

Recent advances in the understanding of biology of MCL cells are offering new perspectives for the design of targeted therapeutic strategies. The $t(11 ; 14)$ (q13;q32) translocation occurs in an immature $B$ cell and results in the ectopic and deregulated expression of cyclin D1 and early expansion of tumor B cells in the mantle zone areas of lymphoid follicles. This translocation is considered a primary pathogenesis event that deregulates the cell-cycle control, probably by overcoming the suppressor effect of retinoblastoma 1 (RB1) and cell-cycle inhibitor p27. Since defects in cell cycle regulation and apoptosis are primary events in MCL, small-molecule inhibitors of Cdks may play an important role in the therapy of this disorder. Earlier data from our laboratory has shown that P276-00, a Cdk inhibitor inhibits cyclin D1 and down regulates Cdk4 specific phosphorylation of $\mathrm{RB}$ at Ser780 (pRb $\left.{ }^{\text {Ser780 }}\right)$ along with up regulation of $\mathrm{p} 27$ and p21 in breast and lung cancer cell lines [20,21]. Hence, the present study was designed to evaluate the therapeutic implication of P276-00 in MCL.

In this study, we first demonstrated that P276-00 directly inhibited the growth of three MCL cell lines in time and dose dependent manner. It has shown potent cytotoxicity against both nodal and blastic variant MCL cells indicating potential therapeutic implication. Interestingly, our earlier data $[20,22]$ showed that the same treatment did not affect the growth of normal resting hPBMNCs 
A
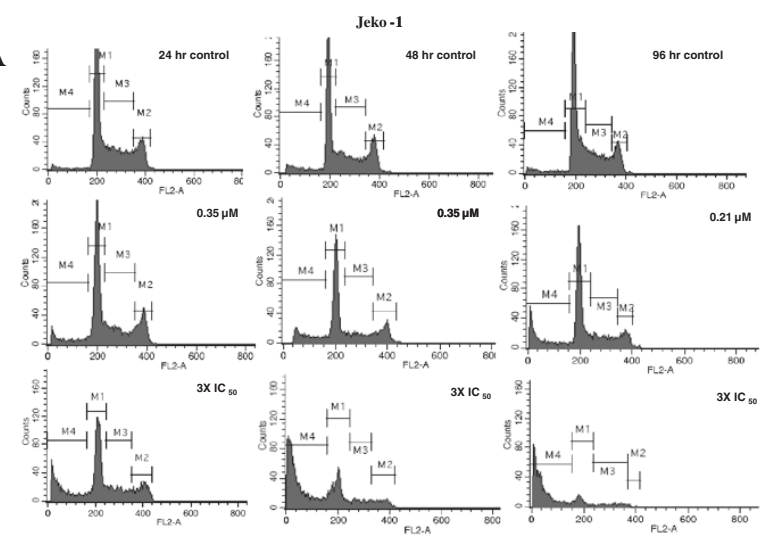

B
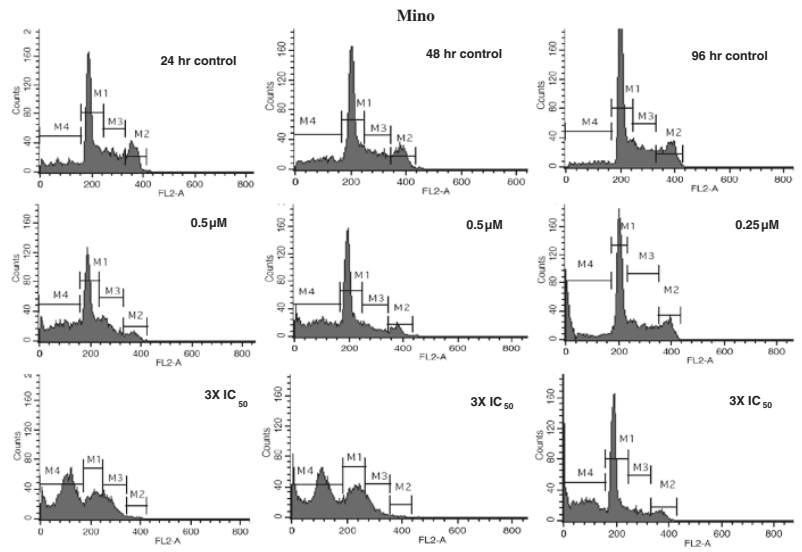

C
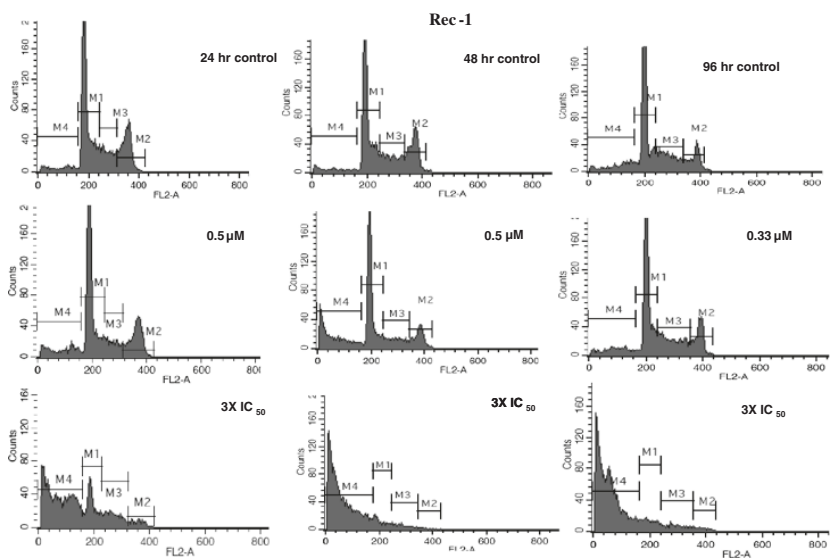

D

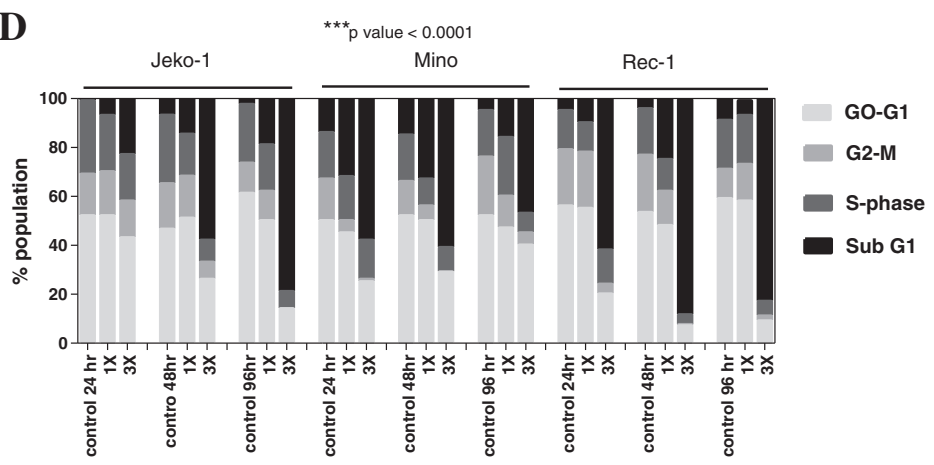

Figure 3 (See legend on next page.) 
(See figure on previous page.)

Figure 3 Effect of P276-00 treatment induces apoptosis in MCL cell lines : Cell-cycle analysis by PI staining was performed on (A) Jeko-1, (B) Mino and (C) Rec-1, cultured with media alone or IC 50 and $3 X I C_{50}$ of P276-00 for the 24, 48, and 96 h time point. Cells were processed and analyzed by flow cytometry as described in Materials and Methods. Histogram shows shift of cells from G1 phase (M1) to apoptotic phase (M4). Results shown are representative of three independent experiments. Percent change in G1 or S-phase cells was normalized to DMSO vehicle control (D) Compiled data shows dose and time dependant increase in apoptotic cells in all three MCL cells $\left({ }^{* *} p<0.0001\right)$.

A

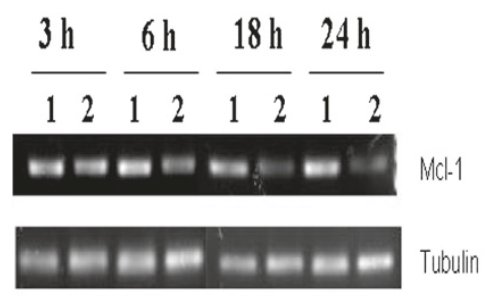

C

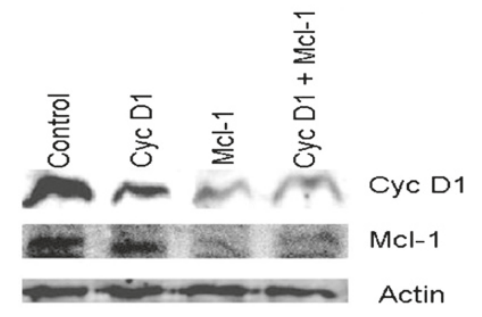

D

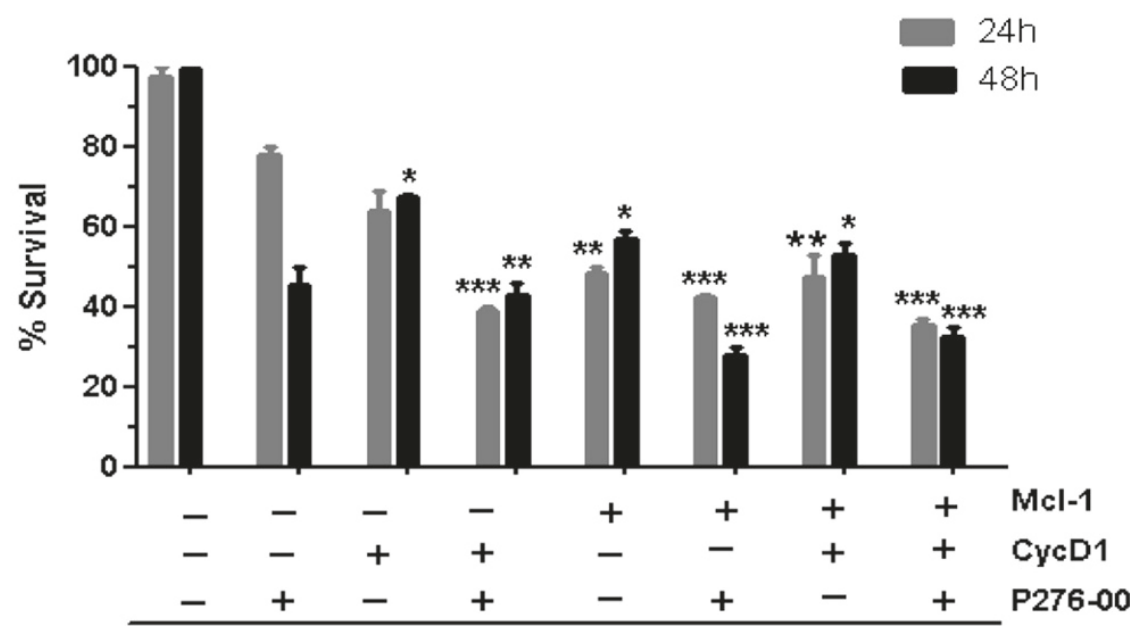

B

Mcl-1 mRNA expression

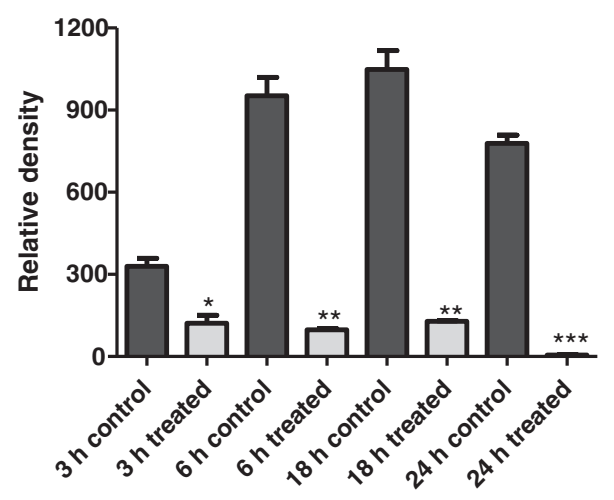




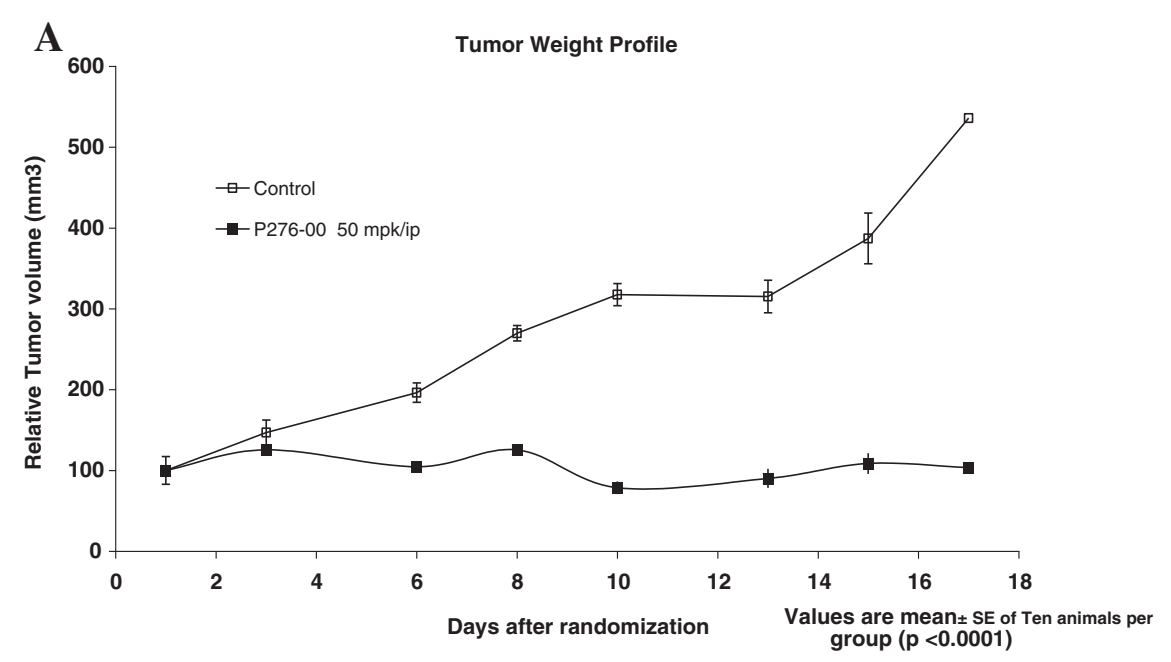

B

Survival of Jeko- $1 \mathrm{n}=6 /$ group

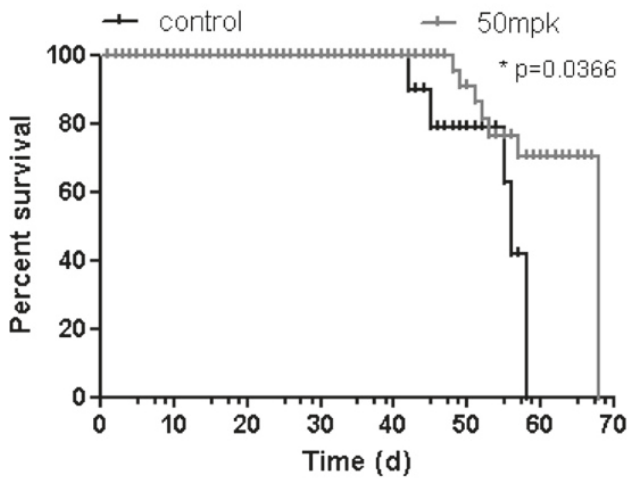

C

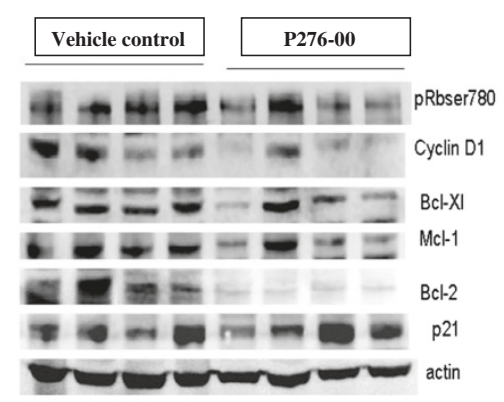

E (Intratumoral levels of P276-00)

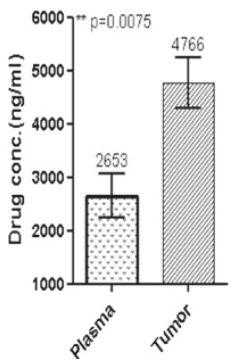

D

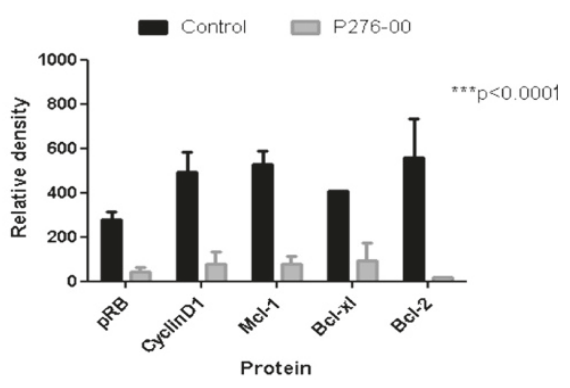

Figure 5 (See legend on next page.) 
(See figure on previous page.)

Figure 5 P276-00 in vivo anti-tumor efficacy as single agent and its pharmacokinetics/pharmacodynamic relationship. (A) Treatment with P276-00 in Jeko-1 xenograft by i.p. injection showed significant dose dependent tumor growth inhibition of $91 \%$ at $50 \mathrm{mpk}$ with tumor regression on day $8\left(^{* * *} p=0.0001\right)$ and stable disease throughout the schedule (B) P276-00 prolonged survival of tumor bearing SCID mice by two weeks compared to untreated shown using Kaplan Meier survival curve $\left({ }^{*} p=0.0366\right)$ (C) Protein expression analysis of the tumor samples showed target engagement with marked inhibition of cell cycle regulating and antiapoptotic proteins (D) Densitometric analysis of protein expression in tumor samples showing decrease in levels of proliferation and survival markers (E) High intratumoral levels of P276-00-detection by LC-MS for Jeko-1 tumor samples.

suggesting a good therapeutic window. Further, this compound was able to induce apoptosis and caused an accumulation of cells in G1-S phase of the cell cycle in all three MCL cell lines. This could be due to significant reduction in cell cycle regulators viz. protein levels of cyclin D1, pRb ${ }^{\text {Ser780 }}$ and Cdk4 along with down regulation of antiapoptotic protein Mcl-1. Earlier studies have also shown that Cdk inhibitors CYC202 and flavopiridol decrease the levels of cyclin D1 in MCL [6]. Moreover P276-00 showed down regulation of an important regulator, $\mathrm{pRb}^{\mathrm{Ser} 780}$ and total $\mathrm{Cdk} 4$ which initiates the G1-S transition of the cell cycle. Knockdown of Mcl-1 using siRNA in MCL cells lead to significant apoptosis indicating its importance in cell survival. Similar results have been observed by Chen et al previously [9]. We have shown that in addition to cell cycle protein levels, P276-00 also inhibited transcription of key survival protein Mcl-1 which could be attributed to P276-00 effect on Cdk9 inhibition [22]. Earlier reports indicated that MCL cells use multiple survival pathways to evade apoptosis, which possibly renders them resistant to a variety of therapeutic interventions and hence targeting cyclin D1 alone may not prove to be an effective strategy, especially for MCL blastic variant in which expression of Mcl-1 has been shown to be associated with aggressive phenotype $[9,19]$. Rapid apoptosis in Jeko-1

A P276-00 in combination with Bortezomib (100nM)
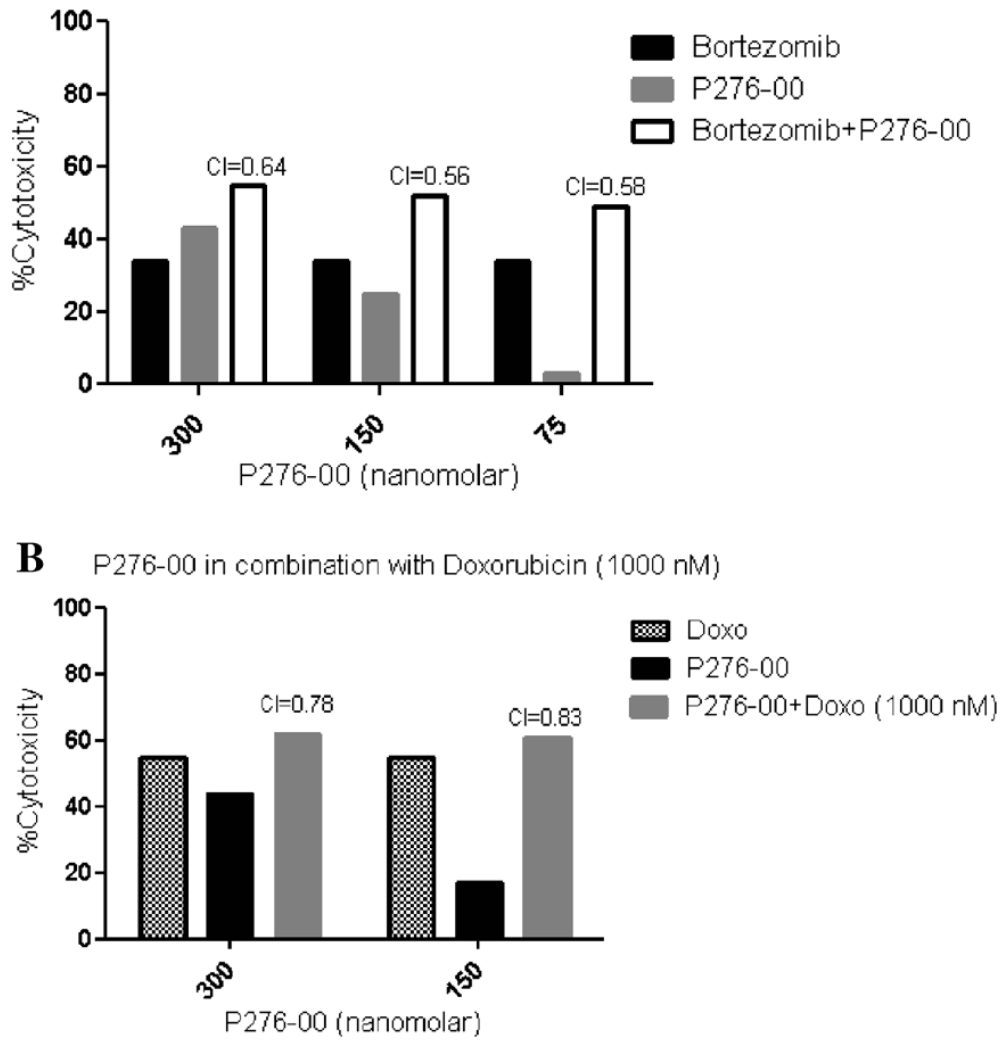

Figure 6 Combination studies of standard therapies with P276-00. P276-00 has synergistic anti MCL activity when combined with bortezomib at $100 \mathrm{nM}$ and doxorubicin at $1000 \mathrm{nM}$. Combination index (Cl) was calculated using CompuSyn software. Data for (A) Bortezomib $(100 \mathrm{nmol} / \mathrm{L})$ and $(\mathbf{B})$ Doxorubicin $(1 \mu \mathrm{mol} / \mathrm{L})$ are represented, with synergism noted at given concentration of P276-00 and Cl of less than 1. 
cells could be attributed to transcription inhibition of short-lived protein Mcl-1.

In addition to deregulated cell cycle control, it is clear that aberrant apoptotic and pro inflammatory pathways play an important role in pathogenesis of MCL [1]. Therefore, it was interesting to understand combination effects of P276-00 with standard-of-care for MCL. Preliminary combination studies of P276-00 with proteasome inhibitor bortezomib and doxorubicin were found to be synergistic. Further potential combination approaches need to be addressed. Notably, triple combination of siRNA for cyclin D1 and Mcl-1, with P27600 is significantly effective as compared to drug alone suggestive of the need for inhibition of multiple pathways for proficient therapy for MCL. Of importance, the in vivo efficacy in MCL xenograft in SCID mice model demonstrates that P276-00 significantly inhibited tumor growth and prolonged the survival of tumor bearing mice. PK-PD studies on the tumor samples clearly demonstrated down regulation of protein levels for cyclin $\mathrm{D} 1, \mathrm{pRb}{ }^{\mathrm{Ser} 780}$ along with antiapoptotic proteins viz. Mcl-1 $\mathrm{Bcl}-2$ and $\mathrm{Bcl}-\mathrm{XL}$. This indicates that the significant antitumor effect is due to frank apoptosis and it was associated with peak P276-00 plasma and tumor concentration of 5-16 $\mu \mathrm{mol} / \mathrm{L}$ in Jeko-1 and Mino tumor samples. Importantly, we observed two times higher parent compound in tumors as compared to plasma indicating that in vivo P276-00 is effective and therapeutic to MCL.

\section{Conclusions}

In summary, we investigated the action of P276-00, a Cdk inhibitor in three MCL cell lines. Our results show that treatment of MCL cells with P276-00 down regulated important proteins which contribute to pathogenesis of MCL viz. cyclin D1 and Mcl-1 along with cell cycle regulators viz. $\mathrm{pRb}^{\mathrm{Ser} 780}, \mathrm{Cdk} 4, \mathrm{Cdk}$. These remarkable in vitro and in vivo efficacies of $\mathrm{P} 276-00$, provides a framework for clinical application as a single agent or in combination with conventional therapies in MCL (Figure 7). Thus these data collectively suggest that by merely decreasing the proliferative and survival signatures of the disease we could possibly have a better overall prognosis of the disease. A phase II study is currently ongoing (http://www. seattlecca.org/clinical-trials/lymphoma-UW09052.cfm).

\section{Methods}

\section{Cell culture and reagents}

Human MCL cell lines Jeko-1, Mino and Rec-1 were obtained from ATCC (Rockville, MD, USA). All three cell lines were cultured in RPMI-1640 medium containing 10\% fetal bovine serum (FBS) (Hyclone, UT, USA), $2 \mathrm{mmol} / \mathrm{L}$ L-glutamine (Gibco, Grand Island, NY, USA), $100 \mathrm{U} / \mathrm{mL}$ penicillin and $100 \mathrm{mg} / \mathrm{mL}$ streptomycin (Gibco). Cells were maintained at $37^{\circ} \mathrm{C}$ in a humidified atmosphere containing $5 \% \mathrm{CO}_{2}$. P276-00 was synthesized at Piramal Healthcare Limited, Mumbai, India, Roscovitine was purchased from Sigma (St Louis, MO, USA). Both drugs were dissolved in dimethyl sulfoxide (DMSO) at a concentration of $10 \mathrm{mmol} / \mathrm{L}$ and stored at $-20^{\circ} \mathrm{C}$ until use; required dilutions were made in culture medium RPMI-1640 immediately before use. All reagents were purchased from Sigma (St. Louis, MO, USA) unless stated otherwise.

\section{In vitro cytotoxicity assay}

Cytotoxicity of P276-00 on MCL cell lines was assessed using a CCK-8 assay according to the manufacturer's instructions (Dojindo), as mention earlier [22]. Each concentration was plated in triplicate. P276-00 was applied at five concentrations $(0.01,0.1,0.3,1$, and $3 \mu \mathrm{mol} / \mathrm{L})$ while roscovitine was at concentrations $(1,3,10,30$ and $50 \mu \mathrm{mol} / \mathrm{L})$. Cells were incubated for 48 and $96 \mathrm{~h}$. At the end of incubation period, CCK- 8 was added $(10 \mu \mathrm{L}$ per well) and absorbance was measured at $450 \mathrm{~nm}$ using a

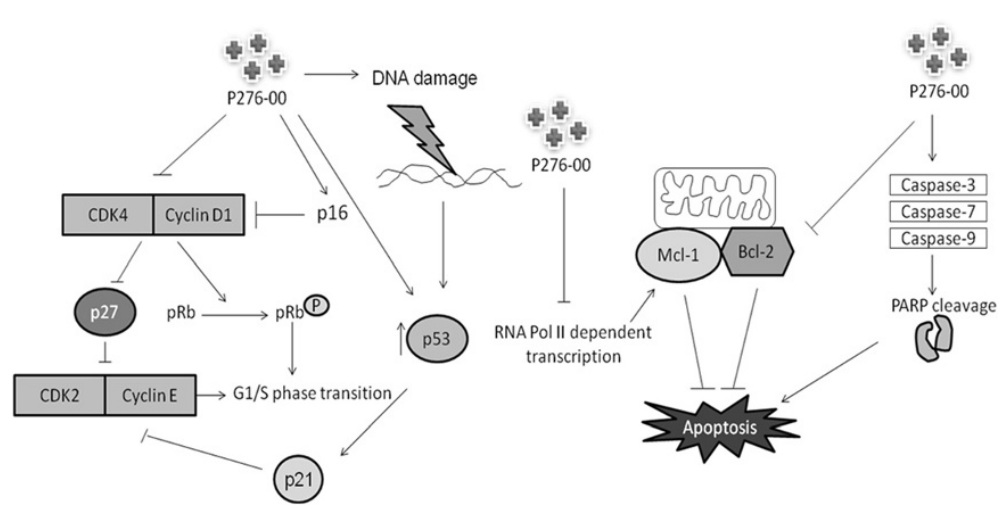

Figure 7 Schematic representation of effect of P276-00 on cell cycle regulator and apoptosis in MCL. P276-00, a Cdk4-D1, Cdk1-B and Cdk9-T1 specific inhibitor showed potent antiprolifeartive effect in MCL cell lines by targeting positive and negative regulators of cell cycle with modulation of apoptosis. 
spectramax microplate reader (Molecular devices, CA, USA). Data was analyzed to determine the $\mathrm{IC}_{50}$ (concentration of compound that inhibited cell growth by $50 \%$ ).

\section{Preparation and analysis of cell lysates by immunoblotting}

The human MCL cell lines were seeded at $1.5 \times 10^{6}$ cells/mL in T-25 flasks and treated with or without $\mathrm{IC}_{50}$ or $3 \mathrm{X} \mathrm{IC}_{50}$ of P276-00 for various time points. Lysates were prepared and western blotting was carried out as described previously [22]. Following antibodies were used: RNA polymerase II CTD phosphoserine 2/5 and Mcl-1 (Cell signaling technology, USA), PARP and Bcl-XL (BD pharmingen, USA), $\beta$-actin (Sigma, MO, USA), Cdk4, pRb ${ }^{\text {Ser780 }}$, p21, p16, p27, p53, Bcl-2, cyclin D1, cyclin T1, anti-rabbit-HRP and anti-mouse-HRP secondary antibodies (Santa Cruz Biotechnology, CA, USA).

\section{Immunofluorescence and confocal laser microscopy}

Mino cells were seeded at a density of $1 \times 10^{6}$ cells per well of six well plate with treated cells exposed to $1.5 \mu \mathrm{mol} / \mathrm{L} \mathrm{P276-00} \mathrm{for} 6 \mathrm{~h}$. Cells were harvested and processed for immunofluorescence as described previously [22].

\section{Analysis of cell cycle distribution by flow cytometry} The human MCL cell lines were seeded in T-25 tissue culture flasks at a density of $0.5 \times 10^{6} / \mathrm{mL}$ and treated with or without (control) $\mathrm{IC}_{50}$ and $3 \mathrm{X} \mathrm{IC}_{50}$ concentrations of P276-00 for $24 \mathrm{~h}, 48 \mathrm{~h}$ and $96 \mathrm{~h}$. Cells were harvested and processed for flow cytometry as described previously [21].

\section{RNA extraction and reverse transcription-PCR}

Cells were treated and harvested identically to those prepared for immunoblotting. Cell pellets were lysed and RNA was extracted using RNAeasy kit (Qiagen, Valencia, USA). Purified RNA was quantitated and assessed for purity by UV spectrophotometry. cDNA was synthesized from $2 \mu \mathrm{g}$ RNA with Superscript III reverse transcriptase (Qiagen). The amplification of each specific RNA was performed in a $20 \mu \mathrm{L}$ reaction mixture containing $2 \mu \mathrm{L}$ of cDNA template, PCR master mix and the primers. The sequences of the primers were as follows:

Mcl-1 Forward: TAAGGACAAAACGGGACTGG; Reverse: ACATTCCTGATGCCACCTTC with annealing temperature of $55^{\circ} \mathrm{C}$ and cycle no. 32, Tubulin Forward: TCTGTTCGCTCAGGTCCTTTTGGCC; Reverse: CGT ACCACATCCAGGACAGA with annealing temperature of $55^{\circ} \mathrm{C}$ and cycle no. 32. The PCR products were loaded onto $2 \%$ agarose gels and visualized with ethidium bromide under UV light. As a control for cDNA synthesis, reverse transcription-PCR was also performed using primers specific for tubulin gene.

\section{siRNA mediated RNA interference}

Jeko- 1 cells were plated in six-well plates with $0.2 \times 10^{6}$ per well in FBS-free and antibiotic-free media. The cells were transfected with siRNA (cyclin D1-specific siRNA or Mcl-1 siRNA or non-specific siRNA, QIAGEN, USA) using Lipofectamine2000 Transfection Reagent (Invitrogen, Carlsbad, CA) as per manufacturer's instructions. For cyclin D1 and/ or Mcl-1 knockdown, the cells were treated with $100 \mathrm{nmol} / \mathrm{L}$ siRNA. After transfection, the next day P27600 was added $(1 \mu \mathrm{mol} / \mathrm{L})$ and the cells were incubated further for another $24 \mathrm{~h}$ or $48 \mathrm{~h}$.

\section{Tumor xenograft model}

Severe combined immunodeficient (SCID) mice were injected in $0.2 \mathrm{~mL}$ volume $(0.1 \mathrm{~mL}$ of the cell suspension containing $1 \times 10^{7}$ cells and $0.1 \mathrm{~mL}$ of Matrigel) s.c. on the right flank. When the tumors attained a diameter of $100 \mathrm{~mm}^{3}$, mice were randomized into 2 groups i.e vehicle control (water) and P276-00 (50 mg/ $\mathrm{kg})$. Both the groups were dosed i.p. with vehicle control and P276-00, formulated in water, daily for 15 consecutive days. Animal survival was plotted using Kaplan Meier survival curve and was monitored for 5 weeks post treatment discontinuation. Tumors from animals were excised at the end of the treatment post $15 \mathrm{~min}$ of dosing. Further tumors were weighed and snap-frozen for protein expression analysis and pharmacokinetic studies. Protein extracts were prepared and subjected to western blot analysis as explained earlier, and probed with different antibodies. Densitometric analysis of western blots was carried out using Image J 1.42 q software. Animals were maintained and experiments were carried out as per the institutional animal ethical committee in compliance with the guidelines of the Committee for the Purpose of Control and Supervision on Experiments on Animals (CPCSEA), India.

\section{Statistical analysis}

Statistical comparison was made using GraphPad PRISM $^{\circledR}$ (versions 3.0 and 5.0, GraphPad Software, Inc., USA) software where one-way and two way analysis of variance (ANOVA) and Tukey's multiple comparison post-tests were used to determine significant differences between several treatment groups. Student's unpaired $t$-test was employed when only two groups were compared. Data are presented as mean \pm S.E.M. of at least three independent experiments with triplicates. Statistical significance was evaluated by calculating $p$ values, where $p<0.05$ was considered statistically significant. $\left({ }^{*} p<0.05 ;{ }^{* *} p<0.01,{ }^{* * * *} p<0.001\right)$. Log-rank test was used 
for the animal survival study and Kaplan-Meier survival curves were generated from this test.

\section{Abbreviations}

PKPD: Pharmacokinetic pharmacodynamic; Cdk: Cyclin-dependent kinase; RB: Retinoblastoma; hPBMNCs: Human peripheral blood mononuclear cells; mg/kg: Milligram per kilogram; LC MS: Liquid chromatography mass spectrometers

\section{Competing interests}

The authors declare that they have no competing interests.

\section{Authors' contributions}

$\mathrm{KJ}$ conceptualized and guided the research project. NS performed experiments viz. cytotoxicity, flow cytometry, in vivo efficacy including PKPD studies and combination studies. SM performed and analyzed western blot, RT-PCR and siRNA experiments. Manuscript was written by NS and KJ. All authors approved the final manuscript.

\section{Acknowledgement}

The work has been supported and carried out at Piramal Healthcare Limited, Goregaon, Mumbai, India. We extend our thanks for the support. Also, we thank Dr. Anagha Damre (DMPK group, Department of Pharmacology) for analysis of the tumor samples and Maggie Rathos for the discussion and comments in combination studies.

\section{Author details}

'Oncology Franchise, Piramal Healthcare Limited, 1-Nirlon Complex,

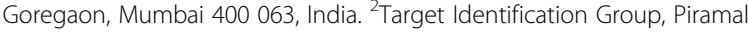
Healthcare Limited, 1-Nirlon Complex, Goregaon (E), Mumbai 400 063, India.

Received: 18 May 2012 Accepted: 16 October 2012

Published: 18 October 2012

\section{References}

1. Jares P, Campo E: Advances in the understanding of mantle cell lymphoma. Br J Haematol 2008, 142:149-165.

2. Liu Q, Alinari L, Chen CS, Yan F, Dalton JT, Lapalombella R, Zhang X, Mani R, Lin T, Byrd JC, Baiocchi RA, Muthusamy N: FTY720 shows promising in vitro and in vivo preclinical activity by down modulating cyclin D1 and phospho-Akt in mantle cell lymphoma. Clin Cancer Res 2010, 16:3182-3192.

3. Ghielmini M, Zucca E: How I treat mantle cell lymphoma. Blood 2009, 114:1469-1476.

4. Norton AJ, Matthews J, Pappa V, Shamash J, Love S, Rohatiner AZ, Lister TA: Mantle cell lymphoma: natural history defined in a serially biopsied population over a 20-year period. Ann Oncol 1995, 6:249-256.

5. Jourdan M, De Vos J, Mechti N, Klein B: Regulation of Bcl-2-family proteins in myeloma cells by three myeloma survival factors: interleukin- 6 , interferon-a and insulin-like growth factor 1. Cell Death Differ 2000, 7:1244-1252.

6. Venkataraman G, Maududi T, Ozpuyan F, Bahar HI, Izban KF, Qin JZ, Alkan S: Induction of apoptosis and down regulation of cell cycle protein in mantle cell lymphoma by flavopiridol treatment. Leuk Res 2006, 30:1377-1384

7. Baran-Marszak F, Boukhiar M, Harel S, Laquillier C, Roger C, Gressin R, Martin A, Fagard R, Varin-Blank N, Ajchenbaum-Cymbalista F, Ledoux D: Constitutive and B-cell receptor-induced activation of STAT3 are important signaling pathways targeted by bortezomib in leukemic mantle cell lymphoma. Haematologica 2010, 95:1865-1872.

8. Goy A, Feldman T: Expanding therapeutic options in mantle cell lymphoma. Clin Lymphoma Myeloma 2007, 7:S184-S191.

9. Chen R, Chubb S, Cheng T, Hawtin RE, Gandhi V, Plunkett W: Responses in mantle cell lymphoma cells to SNS-032 depend on the biological context of each cell line. Cancer Res 2010, 70:6587-6597.

10. Pileri SA, Falini B: Mantle cell lymphoma. Haematologica 2009, 94:1488-1492

11. Camacho E, Hernandez L, Hernandez S, Tort F, Bellosillo B, Bea S, Bosh F, Montserrat E, Cardesa A, Fernández PL, Campo E: ATM gene inactivation in mantle cell lymphoma mainly occurs by truncating mutations and missense mutations involving the phosphatidylinositol-3 kinase domain and is associated with increasing numbers of chromosomal imbalances. Blood 2002, 99:238-244.

12. Hangaishi A, Ogawa S, Qiao Y, Wang L, Hosoya N, Yuji K, Imai Y, Takeuchi K, Miyawaki S, Hirai H: Mutations of Chk2 in primary hematopoietic neoplasms. Blood 2002, 99:3075-3077.

13. Tort F, Hernandez S, Bea S, Martinez A, Esteller M, Herman JG, Puig X, Camacho E, Sanchez M, Nayach I, Lopez-Guillermo A, Fernandez PL, Colomer D, Hernandez L, Campo E: CHK2-decreased protein expression and infrequent genetic alterations mainly occur in aggressive types of non-Hodgkin lymphomas. Blood 2002, 100:4602-4608.

14. de Boer Cl, Krieken J, Schuuring E, Kluin PM: Bcl-1/cyclin D1 in malignant lymphoma. Ann Oncol 1997, 8:109-117.

15. Zukerberg LR, Benedict WF, Arnold A, Dyson N, Harlow E, Harris NL: Expression of the retinoblastoma protein in low-grade B-cell lymphoma: relationship to cyclin D1. Blood 1996, 88:268-276.

16. Jares P, Campo E, Pinyol M, Bosch F, Miquel R, Fernandez PL, Sanchez-Beato M, Soler F, Perez-Losada A, Nayach I, Mallofre C, Piris MA, Montserrat E, Cardesa $\mathrm{A}$ : Expression of retinoblastoma gene product $(\mathrm{pRb})$ in mantle cell lymphomas. Correlation with cyclin D1 (PRAD1/CCND1) mRNA levels and proliferative activity. Am J Pathol 1996, 148:1591-1600.

17. Paoluzzi L, Scotto L, Marchi E, Zain J, Seshan VE, O'Connor OA: Romidepsin and belinostat synergize the antineoplastic effect of bortezomib in mantle cell lymphoma. Clin Cancer Res 2010, 16:554-565.

18. Bertoni F, Ponzoni M: The cellular origin of mantle cell lymphoma. Int J Biochem Cell Biol 2007, 39:1747-1753.

19. Khoury JD, Medeiros L, Rassidakis GZ, McDonnell TJ, Abruzzo LV, Lai R: Expression of Mcl-1 in mantle cell lymphoma is associated with highgrade morphology, a high proliferative state, and p53 overexpression J Pathol 2003, 199:90-97.

20. Joshi KS, Rathos MJ, Joshi RD, Sivakumar M, Mascarenhas M, Kamble S, Lal B, Sharma S: In vitro antitumor properties of a novel cyclin-dependent kinase inhibitor, P276-00. Mol Cancer Ther 2007, 6:918-925.

21. Joshi KS, Rathos MJ, Mahajan P, Wagh V, Shenoy S, Bhatia D, Chile S, Sivakumar S, Maier A, Fiebig HH, Sharma S: P276-00 a novel cyclindependent inhibitor induces G1-G2 arrest, shows antitumor activity on cisplatin-resistant cells and significant in vivo efficacy in tumor models. Mol Cancer Ther 2007, 6:926-934.

22. Manohar SM, Rathos MJ, Sonawane V, Rao SV, Joshi KS: Cyclin-dependent kinase inhibitor, P276-00 induces apoptosis in multiple myeloma cells by inhibition of Cdk9-T1 and RNA polymerase II-dependent transcription. Leuk Res 2011, 35:821-830.

23. Manohar SM, Padgoankar A, Jalota-Badhwar A, Rao SV, Joshi KJ: Cyclindependent kinase inhibitor, P276-00, inhibits HIF-1a and induces G2/M arrest under hypoxia in prostate cancer cells. Prostate Cancer Prostatic Dis 2012, 15:15-27.

24. Chou TC: Drug combination studies and their synergy quantification using the chou-talalay method. Cancer Res 2010, 70:440-446.

\section{doi:10.1186/1476-4598-11-77}

Cite this article as: Shirsath et al: P276-00, a cyclin-dependent kinase inhibitor, modulates cell cycle and induces apoptosis in vitro and in vivo in mantle cell lymphoma cell lines. Molecular Cancer 2012 11:77.

\section{Submit your next manuscript to BioMed Central and take full advantage of:}

- Convenient online submission

- Thorough peer review

- No space constraints or color figure charges

- Immediate publication on acceptance

- Inclusion in PubMed, CAS, Scopus and Google Scholar

- Research which is freely available for redistribution 